\title{
Order of report and ear asymmetry in dichotic listening '
}

ANITA COOPER ${ }^{2}$, KARL ACHENBACH, PAUL SATZ AND C. MICHAEL LEVY DEPARTMENT OF PSYCHOLOGY AND THE CENTER FOR NEUROBIOLOGICAL SCIENCES, UNIVERSITY OF FLORIDA

This study is an attempt to reduce some confusion over reports of an ear asymmetry effect in the dichotic listening paradigm and to assess the criticism that the effect is artifactual. $A$ within-S design was used in which six pairs of digits per trial were presented at 2 pair/sec. When order of report was controlled, a dramatic ear asymmetry and a clear ear order effect was evident. The orthogonality of these effects implies that the asymmetry is not an artifact of order of reporting.

In the last few years an ear asymmetry has frequently been found in dichotic stimulation. This asymmetry has appeared as a superiority of the right ear over the left when Ss have been instructed to recall simultaneously presented, disparate verbal messages. Kimura (1961a, b), using brain-damaged $\mathrm{Ss}$, found superior recall in the ear contralateral to the hemisphere dominant for speech. Since most of her patients had left-brained speech representation (sodium amytal test), the right ear was superior to the left. This ear asymmetry has subsequently been confirmed in a number of studies in which rate (Bryden, 1962; Bartz, Satz, \& Fennell, in press), amount of material (Bryden, 1962; Satz, Achenbach, Pattishall, \& Fennell, 1965), types of material (Bartz, Satz, Fennell, \& Lally, 1967; Bartz et al, in press), instructions (Satz et al, 1965; Achenbach, 1966; Bartz et al, in press), and handedness (Satz et al, 1965, 1967) have been varied.

The concept of an ear asymmetry has sometimes been confused with the ear order effect which was first documented by Broadbent (1954). In his study it was found that, under a free-recall condition, $\mathrm{Ss}$ reported all the information from one ear before reporting any from the other. By varying rate of presentation and amount of material, Bryden (1962) found that the ear order effect was dependent on faster rates of presentation and greater amounts of material.

Recent criticlsm of the concept of ear asymmetry (Inglis, 1966) suggests that the phenomenon is an artifact of orders of report; that is, the "superior" right ear performance is due to the S's tendency to use this ear first in responding to dichotic materials. In fact, when uninstructed as to orders of report, Ss do tend to report from the right ear first more often than from the left. Therefore, at least partially because of the serial order effect, the right ear has been superior to the left in overall recall. The reason, however, for the tendency of Ss to report the right ear first has remained unexplained. In addition, when order of report has been controlled through instruction, the serial-order explanation of the asymmetry has not proven adequate. Satz et al (1965) and Achenbach(1966), using four pairs of digits, demonstrated that the ear asymmetry occurred regardless of which ear was recalled first.

The effects of controlling order of report, however, have not been examined for the six-pair condition. Yet, it is under this condition that the strongest and most consistent ear asymmetry has been shown (Satz et al, 1965, 1967). The present study was designed to determine the effects of controlled orders of reports under the six-pair condition on the presence of the ear asymmetry. Method

The Ss were 21 students at the University of Florida who were selected on the basis of a questionnaire which excluded all but those Ss who were right-handed, had no known family history of sinistrality, and had no known auditory impairment.

The stimulus tape had 25 trials with six pairs of digits per trial. The digits were recorded at a rate of two pairs/sec on a Wollensak tape recorder, and there was a $15 \mathrm{sec}$ intertrial recall interval. The first five trials were practice trials designed so $S$ could become familliar with the apparatus. The stimull were delivered through Koss Pro-4 stereophonic earphones in such a way that one half of each pair of digits was heard in each ear.

Immediately preceding each trial the word "right" or "left" was spoken to indicate which channel S should report first. These directions were recorded in such a way that within the 20 test trials, each command was given 10 times. The pattern used in recording the commands made it impossible for $S$ to anticipate the instructions.

\section{Results}

The results showed that both a strong serial order effect and an ear asymmetry occurred in this dichotic listening task. More responses were correctly recalled per $S$ from the channel reported first $(\bar{X}=4.42)$ than from the channel reported second $(\overline{\mathrm{X}}=1.31)$, regardless of which ear the digits entered $(F=328.05$, df $=1 / 20$, $p<.01)$. When the immediate and delayed channels were combined, recall was found to be better for digits presented to the right ear $(\overline{\mathrm{X}}=3.14)$ than to the left $(\bar{X}=2.58 ; \quad F=11.99$, of $=1 / 20, p<.01)$. Moreover, the ear asymmetry was reliable over orders of report. Comparing the channels reported initially, the recall from the right ear was superior to the left $\left(\bar{X}_{\mathrm{s}}=4.71\right.$ and 4.11 , respectively; $t=5.50$, df $=20, p<.01$ ). Likewise, when the delayed channels were examined, recall was better for digits presented to the right ear than to the left ear $(\overline{\mathrm{X}} \mathrm{s}=1.56$ and 1.06 , respectively; $t=4.50$, 
$\mathrm{df}=20, \mathrm{p}<.01)$. The interaction of order of report and ear asymmetry fell far short of significance.

\section{Discussion}

The results of this study extend and clarify results obtained from earlier experiments involving dichotic stimulation. It is evident from the results obtained in this study that both a serial order effect and an ear asymmetry occur. When both ears had the advantage of being reported first, a marked right ear superiority was apparent. By the same token, when both ears were placed at an equal disadvantage, by both being reported second, the right ear was still superior to the left. Thus, the serial order effect and the ear asymmetry are orthogonal sources of variation in this paradigm.

The degree of ear asymmetry and the manner of its manifestation seems to be dependent upon many factors of the experimental design: list length, types of material (digits, syllables, words, melodies), rate of presentation (two pair/sec is optimal), as well as instructions controlling order of report. Even the time at which the instructions are given may affect the appearance of the asymmetry. Earlier studies (Satz et al, 1965; Achenbach, 1966; Bartz et al, in press) controlled order of report between $\mathrm{Ss}$; that is, one group always reported the left ear first, the other group always reported the right ear first. The present study controlled order within-Ss by varying the instruction before each trial. In both paradigms the ear asymmetry appeared as orthogonal to the serial order effect. A recent study, however, reported by Oxbury, Oxbury, \& Gardiner (1967), failed to obtain a clear ear asymmetry when the instructions for report were given after each trial. The right ear was, however, more dependent upon the recall conditions than was the left, indicating an asymmetry of sorts. Unfortunately, other aspects of their design make interpretation of their data difficult. Their rate of presentation $(90 / \mathrm{min})$ was much slower than the optimal rate for channel separation (two pair/ sec). Also, they used only three pairs of digits per trial, minimizing the opportunity for signiflcant differences.

Despite the dependency of the manifestation of the ear asymmetry upon the stimulus and experimental conditions, it seems certain that it is a real phenomenon, not an artifact. The serial order explanation given by Inglis (1966) does account for some aspects of the free-recall situation but does not explain the Ss' tendency to choose the right ear to report first. This tendency itself may be a manifestation of the underlying asymmetry. Similarly, the suggestion by Oxbury et al (1967) of an "attentional bias" toward the right ear clearly invokes an asymmetry of central mechanisms. The present study, the control of orders of report and the use of optimum rates of presentation and amount of material has enabled the ear asymmetry to penetrate the mask of the serial order effect. Thus, the right ear superiority in both intial and delayed channels cannot be dismissed as an artifact.

\section{References}

ACHENBACH, K. The effect of repetition on short-term storage in dichotic listening. Unpublished doctoral dissertation, University of Florida, 1966.

BARTZ, W., SATZ, P., \& FENNELL, EILEEN. Grouping strategies in dichotic listening: the effects of instructions, rate and ear asymmetry. J. exp. Psychol, 1967, in press.

BARTZ, W., SATZ, P., FENNELL, EILEEN, \& LALLY, J. Meaningfulness and laterality in dichotic listening. J. exp. Psychol., 1967, 73, $204-210$.

BROADBENT, D. E. The role of auditory localization in attention and memory span. J. exp. Psychol, 1954, 47, 191-196.

BRYDEN, M. P. Order of report in dichotic listening. Canad. J. Psychol., $1962,16,291-299$

INGLIS, J. Some sources of variation in dichotic listening performance. Paper read at Midwest. Psychol. Assoc., Chicago, May, 1966.

KIMURA, DOROTHY. Some effects of temporal lobe damage on auditory perception. Canad. J. Psychol, 1961a, 15, 156-165.

KIMURA, DOROTHY. Cerebral dominance and the perception of verbal stimuli. Canad. J. Psychol, 1961b, 16, 18-22.

OXBURY, SUSAN, OXBURY, J., \& GARDINER, JANE. Laterality effects in dichotic listening. Nature, 1967, 214, 742-743.

SATZ, P. ACHENBACH, K., \& FENNELL, EILEEN. Correlations between assessed manual laterality and predicted speech laterality in a normal population. Neuropsychologia, 1967, in press.

SATZ, P., ACHENBACH, K., PATTISHALL, E., \& FENNELL, EILEEN. Order of report, ear asymmetry, and handedness in dichotic listening. Cortex, 1965, 1, 377-396.

\section{Notes}

1. This research was supported in part by NSF grant GY-995 and NIH grant MH 12046 and by funds provided by the Institute of Social Sciences of the University of Florida. The authors wish to express their appreciation to Mr. Dennis Jowaisas and Mrs. Eileen Fennell for as sistance rendered in the preparation of the stimulus materials.

2. National Science Foundation undergraduate research participant, 1966-1967. 